\title{
6 Agency and atmospheres of inclusion and exclusion
}

\author{
Joel Krueger
}

\section{Introduction}

Atmospheres seem to be everywhere. They are a central part of everyday life. We make decisions about who to spend time with, what to put on our walls, and where to eat based on atmospheres we associate with people, things, and spaces. In this way, atmospheres shape our experience and behaviour. However, the link between atmospheres and agency has been relatively underexplored in the philosophical literature. Much of the debate instead concerns the nature of atmospheres, what sort of things they are.

This focus on the ontology of atmospheres is a rich and philosophically substantive area of work. However, in what follows, I argue that it potentially overlooks important insights into the regulative power of atmospheres, that is, their capacity to shape the things we do and the ways we connect (or fail to connect) with others. Atmospheres do things. They actively shape experience and behaviour - and crucially, they open up (or close down) forms of social connectedness. They do these things, I argue further, because atmospheres don't merely provide affective colour or texture. They also furnish possibilities - possibilities that help or hinder us as we find our way in the world. I unpack this claim by considering atmospheres as "affective arrangements" (Slaby, Mühlhoff, and Wüschner 2017). Along the way, I develop a distinction between "atmospheres of inclusion" and "atmospheres of exclusion," and I apply this distinction to two case studies: Sara Ahmed's critical phenomenology of "stopped bodies," and social difficulties in autism. Both of these cases, I conclude, help to highlight the deep connection between atmospheres and agency.

\section{Preliminary remarks}

We often speak of atmospheres as though they pick out some well-defined entity - a quality, feature, attribute, or presence that attaches to the people, things, and spaces we encounter in everyday life. We talk about the tranquil atmosphere of a spring morning or lush park. A child can radiate an atmosphere of boundless curiosity, hope, innocence, and enthusiasm. 
The family dog can seem trusting and earnest or skittish and twitchy. A piece of music might emanate a sombre or uplifting atmosphere. A classroom can feel lively and inclusive, or threatening and closed-off to open inquiry. Some may experience a family dinner as authentic, loving, spontaneous, and warm; for others, it might feel grim and stilted. Homes, workplaces, churches and temples, restaurants, heritage sites, sports venues, stores, clubs, museums, theatres, factories, music venues, parks, cities, persons, activities, and communities - among many other things - are all said to have distinctive atmospheres.

When we speak of atmospheres in everyday life, we generally don't simply take an aesthetic interest in them the way, say, we might view a work of art (although we can, of course, consider atmospheres from a purely aesthetic point of view). Our interest tends to be more concrete. This is because atmospheres aren't causally inert. They pervade everyday life in ways that shape our evaluations and behaviour. In this way, they can be said to have practical significance.

For example, we might avoid courses taught by a prickly professor who, despite their technical brilliance and international prestige, creates a notoriously unpleasant classroom atmosphere. We may skip a restaurant with well-prepared food because we don't like the colourless or outof-date atmosphere (although such an atmosphere may, for some, be an attractive part of its quirky or kitschy charm), or routinely work in a coffeehouse with middling coffee because we like the cosy atmosphere and find it conducive to working. The key point-important for what follows - is that atmospheres do things. They envelope us, press upon us, and in so doing play an important role in shaping how we evaluate and get on in the world. They help or hinder as we "find our way," as Sara Ahmed (2006) puts it.

Yet, despite the ease with which we speak of atmospheres and their presumed ubiquity, there is, nevertheless, surprisingly little consensus about what atmospheres are. Atmospheres are now increasingly discussed in a variety of disciplines and debates, from architectural studies, aesthetics, and management studies to psychology, geography, anthropology, and sociology (see Osler and Szanto (this volume) for a helpful overview). Discussions are also on the rise in philosophy, as the present volume attests. However, despite this increased attention, there is still widespread recognition that atmospheres are "slippery" phenomena (Böhme 1993), difficult to pin down with ontological precision. Part of this slipperiness comes from the fact that, as we've already noted, atmospheres traverse distinctions between people, things, and spaces (Anderson 2009). It's possible that most things could be described as atmospheric.

The way we talk about atmospheres in both academic discourse and everyday life highlights this ontological ambiguity. On the one hand, atmospheres are often spoken of as though they have a mind-independent reality. They are said to be out in the world, features of the natural 
and built environment that "seem to fill the space with a certain tone of feeling like a haze" (Böhme 1993, 113-114). This way of speaking has led some to characterise atmospheres as "quasi-objective" (Böhme 2006) or "quasi-things" (Griffero 2014). Similarly, Schmitz (2019) characterises atmospheres as a kind of pre-personal affectivity that circulates through public spaces. However, there is, on the other hand, also recognition that atmospheres are experiential phenomena; they are felt. It seems puzzling to think of an atmosphere as existing somehow out in the world without the presence of a subject (or subjects) who feel it. Additionally, the descriptive richness and specificity of atmospheric qualities we ascribe to people, things, and spaces-e.g., serene, homely, strange, stimulating, holy, melancholic, uplifting, depressing, pleasant, moving, inviting, erotic, collegial, open, sublime, etc. (Böhme 1993) - highlights the fact that atmospheres are, in some important sense, modes of encounter (Osler 2021). They are ways that, as embodied subjects, we experience our world, as well as our relation to that world and the people in it. In this way, atmospheres seem to sit uneasily between purely subjective or objective characterisations (Slaby 2019).

I have neither the interest nor the ability to sort out this ambiguity in what follows. Again, this is because my focus is not so much on what atmospheres are but rather what they do. I am specifically concerned with the interrelation between atmospheres and agency. The latter, as I use the term here, encompasses both action and affect. Atmospheres do things by animating and regulating actions at both individual and collective levels. They also animate and regulate affective experiences - again, at both individual and collective levels. Atmospheres do this regulative work by opening up - and also closing down-possibilities for emotional experience, behaviour, and social connection.

In light of my focus on agency, I will adopt a relational conception of atmospheres. Atmospheres, as I think of them, are tied to the world; they are rooted in features of the natural and built environment. These natural, structural, and organisational features are what make certain kinds of atmospheric experiences - including the emotional expression and behaviour that are part of these experiences-possible. They are what give bits of the world a distinctive "tone of feeling." However, these features are, on their own, insufficient to generate atmospheres. Bits of the world may be configured in ways that are poised to potentially generate atmospheric experiences. But atmospheres only arise if subjects are also present and poised to potentially engage with them in some way. Atmospheres, as I speak of them, are intrinsically experiential. Again, it is telling that many of our descriptions involve phenomenal concepts. We try to get a grip on the vagueness and ontological ambiguity of atmospheres by tracing them back to how we experience and live through them. When describing atmospheres in everyday life, we tend to describe both features of the world as well as our felt connection to those features. 


\section{Atmospheres as affective arrangements}

With that background in place, I now turn to a more focused consideration of atmospheres and how they relate to agency. I will try to side-step some of the ontological puzzles mentioned above by thinking about atmospheres in the context of recent interdisciplinary approaches to situated cognition - and more precisely, situated affectivity (e.g., Colombetti and Krueger 2015; Colombetti and Roberts 2015; Griffiths and Scarantino 2009; Krueger 2014b; Saarinen 2020; Slaby 2014; Stephan, Walter, and Wilutzky 2014; von Maur 2021). For these situated approaches, moods, emotions, and other forms of affective experience are driven, manipulated, and sustained-over multiple timescales - by features of an individual's social and material environment. Accordingly, a full account of emotions, for example, cannot be given by focusing on the individual alone (i.e., their brain, central nervous system, or even their body and its expressive capacities). This is because the people and things an individual interacts with transform her emotional capacities in fundamental ways. Bodies fit into, and become dynamically "coupled" with, resources in their environments (e.g., tools, technologies, props, practices, other people) in ways that animate and regulate their emotional experience and behaviour (Colombetti 2016). The ongoing input and support of these environmental resources-such as portable music listening technologies, which are powerful tools for on-demand emotion-regulation (Krueger 2014a) - allows her to realise otherwise inaccessible forms of experience and expression.

Within this situated context, Slaby and colleagues have recently developed the concept of "affective arrangements" (Slaby, Mühlhoff, and Wüschner 2017). For my purposes, affective arrangements are kinds of atmospheres. They determine both the overall feel and affective tonality of specific locales, as well as what sort of emotion-driven behavioural and social possibilities are present (or absent) within those locales. ${ }^{1}$ Affective arrangements are made up of "ensembles of diverse material forming a local layout that operates as a dynamic formation, comprising persons, things, artifacts, spaces, discourses, behaviors, and expressions in a characteristic mode of composition and dynamic relatedness" (4). Affective arrangements come in many forms and degrees of intensity. They are nearly ubiquitous in everyday life. And they encompass a range of diverse phenomena: things like corporate work environments (from factories to white-collar work to stock market trading floors), public transportation, street corners, commercial environments (shopping malls, sports stadiums), organisational settings like classrooms, lecture theatres, and worship spaces, as well as both the ritualistic practices that unfold within these myriad spaces (ceremonial regimes like Christmas, Ramadan, election campaigns, birthday parties, baptisms, funerals, etc.), along with the artefacts that support these practices (5).

The key idea here is that affective arrangements shape the form and dynamics of how bodies feelingly fit into - and come to feel at home within - the 
part of the world these arrangements carve out. ${ }^{2}$ They do so by actively regulating the emotional experiences and behaviour of the individuals who inhabit them. In this way, affective arrangements modulate our agency; they shape how we feel and find our way, including how we find our way alongside others. They have this powerful regulatory impact on us, Slaby and colleagues argue, because affective arrangements are "always in operation, always 'on.' It is the ongoing, 'live' affective relations within the arrangement that constitutes zones of higher relative intensity compared to what is outside" (6). So, dynamic styles of bodily comportment and performative emotional expression appropriate in, say, a raucous pub or restaurant during a night out with friends will not fit into the more sober and serious affective arrangement of a corporate office, mosque, or academic lecture hall. Bodily styles welcome in the former will be actively discouraged in the latter. Accordingly, insofar as we are sufficiently responsive to the norms running through these different arrangements, transitioning from one to the next will actively modulate our agency and affect.

There is another important point to be made. In dynamically shaping our experience and behaviour this way, affective arrangements also shape the character and intensity of the kinds of interpersonal connections we develop within these arrangements. Affective arrangements open up-and in ways explored below, close down-social possibilities, ways to connect and share with others.

For example, in her ethnographic work on work cultures, Melissa Gregg observes that increased emphasis on the affective value of "intimacy" in white-collar work relationships has, among other things, led to a willingness to open up one's home and personal life to work colleagues and professional responsibilities. This opening up occurs when we buy into-or are pressured to buy into - the importance and practice of full-time connectivity. Gregg found that:

[T] he social bonds developed between co-workers in the office are a contributing factor in extending work hours. Loyalty to the team has the effect of making extra work seem courteous and common sense ... [even] when loyalties lie not with the organization or even necessarily the job, but with the close colleagues who are the main point of daily interaction.

(Gregg 2011, 85)

Via always-on communication technologies like smartphones, email, and chat apps, we feel an immediate - and intimate - sense of connectedness with work colleagues. If we have a question or request, we know that we can almost always get a prompt response. But this felt intimacy does not simply arise from the practical ease with which we exchange information. It also arises, Gregg argues, from the affectively saturated experience of "presence bleed": the experience "whereby the location and time of work become 
secondary considerations faced with a 'to do' list that seems forever out of control" (2). We respond to email over the weekend, see other colleagues engaging in work activities in real-time (via active email threads, shared documents, etc.) and feel compelled to be a loyal and supportive team member. So, we join in. The experience of presence bleed in this way generates a local instantiation of a workplace arrangement now embedded in our home, no longer confined to the walls of the office.

This local arrangement modulates our agency. Even during our "down time," we feel anxious and compelled to quickly respond to email exchanges before we get left out of decision-making processes. And it also modulates our emotions. We feel urgency to participate, anxiety when we don't (or if we're delayed), and guilt, remorse, and a sense of disloyalty for letting team members down if we take the weekend off while pings on our phone remind us that work is pushing forward without us.

As this example indicates, affective arrangements bring bodies into social alignment with one another (even when those bodies are physically dispersed). They coordinate patterns of shared experience and behaviour. This alignment happens not only because arrangements furnish material resources (e.g., always-on communication technologies) to make this happen. They also generate and maintain normative expectations that orient bodies within a given material arrangement (i.e., they determine what to do, and how and when to do it), as well as signal approval or disapproval for the way a given body is falling into line — or, conversely, failing to do so (e.g., via giving or withholding promotion or access to VIPs and higher-ups within the organisation).

In this way, arrangements feelingly orient the bodies they come into contact with. This orientation helps bodies fit into their world in different ways. This alignment can be a good thing, such as the way affective arrangements of a nightclub, worship space, or rehab facility can bring bodies into intense modes of connectedness and shared experience that promote wellbeing. However, as the previous example indicates - and as I examine in more detail below-affective arrangements can also have a disorienting effect. They may scaffold the development of unhealthy habits, practices, and forms of self-experience (Maiese and Hanna 2019). One reason for this is that affective arrangements are fundamentally porous. They often bleed into other spaces and arrangements in ways that leave bodies disturbed, restless, unsettled, or on-edge-that is, feeling not fully at-home wherever they happen to be (Slaby 2016).

To sum up, the notion of "affective arrangements" is useful here for several reasons. First, it helpfully captures the dynamic and relational conception of atmospheres I endorsed above. Within affective arrangements like workplaces, museums, gambling casinos, and rehab facilities, individuals are, quite literally, actively arranged. Bodies act on their local arrangements and the resources they furnish in order to regulate their experience and behaviour. However, these same arrangements, in turn, act on them. As 
we've seen, the sociomaterial and normative configuration of an arrangement "brings multiple actors into a dynamic, orchestrated conjunction, so that these actors' mutual affecting and being affected is the central dimension of the arrangement from the start" (Slaby, Mühlhoff, and Wüschner 2017, 5).

Second, the notion captures the way that affective arrangements are both fixed and open-ended. As the presence bleed example indicates, affective arrangements may begin in one location, such as a specific workplace. However, material resources (e.g., Internet-enabled communication technologies) allow them to expand their ambient range. Affective arrangements can infiltrate a variety of other arrangements; in so doing, they adapt over time and take on new forms. In this way, arrangements are performatively and temporally open-ended. Working from home will involve performative dynamics different from those found between office walls (e.g., responding to email while making dinner or watching a movie on the couch). The normative form and force of a given arrangement can, in this way, remain relatively fixed even while its performative dynamics fluidly evolve and adapt in context-specific ways.

Third, as the previous point indicated, affective arrangements are nested phenomena. One arrangement can fit into the general contours of another. A local instantiation of a workplace arrangement, for instance, can spring up at home within the contours of a domestic arrangement. Again, this is because they are fluid and adaptable. Much of their regulative power and potency, therefore, comes from their capacity to infiltrate and spring up within pre-existing arrangements. As we've seen, this can be a good thing. It can help bodies feel at home in the world. A gay Christian, for example, may find comfort and support in certain online communities and spaces that are not available to her in her offline world. This online support may, in turn, help her feel more at home as she navigates intolerance in her offline world. She can access it on an as-needed basis. Online worlds are kinds of affective arrangements that often bleed into and infiltrate our offline experiences and behaviour. ${ }^{3}$ But as we've already seen, affective arrangements can also have a negative impact. They can disturb and disorient bodies and dramatically limit or close down possibilities for action and social connection. Affective arrangements have political consequences. I turn to a more focused consideration of these themes now.

\section{Atmospheres of inclusion and exclusion}

I now turn to a more focused consideration of the idea that affective arrangements allow bodies to extend and fit into them in specific ways. I will do so by exploring how certain arrangements are configured in ways that do not afford an easy "fitting into" for certain kinds of bodies. Such arrangements disorient certain kinds of bodies and, in so doing, disturb their sense of embodiment, agency, and affect at a deep level. They place bodies in a state 
of perpetual discomfort. As we'll see, sometimes this discomfort is intentional; sometimes it's not. This focus on disorientation and discomfort will open up yet another way of thinking about how atmospheres do things in and to the bodies that inhabit them. Two examples will be illustrative: Sara Ahmed's critical phenomenology of disorientation and "stopped" bodies and a phenomenological approach to social difficulties in autism.

We spend our days finding our way through different kinds of affective arrangements. As we've seen, many arrangements are designed to make us feel at home in the world. They orient us and help us find our way by guiding and shaping our emotions and sense of bodily agency. Moreover, these arrangements have an important social function. They create what we might refer to as atmospheres of inclusion.

Atmospheres of inclusion are designed to bring people together, to coordinate their experiences and behaviour, and in so doing enrich and intensify their sense of interconnectedness. They help us find our way to and with others. The affective arrangement of a worship space like a cathedral, for instance, may furnish resources for solitary experiences like quiet prayer, reflection, and confession. However, other aspects of this arrangement are deliberately configured to bring people together: from ritualistic and liturgical practices (singing, chanting, reciting the Nicene Creed), to myriad visual markers (icons, paintings, baptismal fonts, gravestones) and organisational features of the nave and other spaces. All of these things collectively remind individuals that they share a common space; they are participating in a historical affective arrangement shaped by a rich tradition of practices and experiences undertaken by people with shared beliefs. In other words, this arrangement helps people find their way through a shared religious form of life.

So, atmospheres of inclusion not only make us feel at home in an individual sense. They also make it clear that we are at home in a world with others. Part of their orienting function is to provide cues that ours is a landscape of shared arrangements that bodies can together fit into and take shape in. This important social-regulative work that affective arrangements do is often so pervasive and subtle that it is transparent to us. It is easy to overlook and take for granted. However, there are occasions when we do become acutely aware of it and the social possibilities it presents. Often, this happens when we lose access to it. We become aware of the social and regulative character of affective arrangements when, as we try to find our way, we become disoriented.

I've already used the term "disorientation" at several points in the discussion. To clarify. I'm using it in a similar way to Ahmed (2007). Disorientation involves a kind of discomfort, a feeling of not knowing how to find one's way. But the experience of disorientation I'm referring to involves more than just getting lost because one lacks the relevant information, such as when we try to navigate a new city for the first time, follow an academic talk when we don't know the relevant literature, or even the disorientation and irritation we feel when puzzling our way through a philosophical problem. These 
are cases of epistemic discomfort. They involve the "irritation of doubt," as Peirce says, that "causes a struggle to attain a state of belief" (quoted in Tschaepe 2021, 2).

Cases of epistemic doubt are an important part of everyday life. They motivate us to do things in order to learn about ourselves and the world more generally. Accordingly, they often have a bodily or behavioural dimension. If I'm unfamiliar with the layout of a city, I can use a map, smartphone, or ask a local for help finding my way. If I don't know how to fix a sink, I can watch YouTube videos or call a plumber. However, in contrast to epistemic discomfort, what I have in mind here-again, following Ahmed-is something slightly different: a richer felt sense that one is no longer able to find one's way. And to continue with a theme discussed previously, a central part of its character involves a kind of bodily discomfort. More precisely, it is a kind of bodily discomfort that can be present even in the absence of epistemic discomfort.

By "bodily discomfort" I do not mean to suggest that his discomfort is necessarily tied to a specific sensation or part of one's body (e.g., a sore throat, muscle cramp, or irritation that one's shirt doesn't fit quite right). Nor is it necessarily tied to illness-although the discomfort of illness can, like the discomfort I am concerned with, make us feel deeply at odds with both our body and the surrounding environment (Carel 2016; Svenaeus 2019). The bodily discomfort and disorientation I have in mind is rather a global sense of not feeling at home in a particular space-feeling, that is, somehow bodily out of sync with or affectively unsettled within the arrangement one happens to occupy at that moment. This experience is multidimensional, and comes in different intensities, degrees, and durations (Tschaepe 2021). For example, a new hire may initially feel bodily out-of-sync with the rhythms, practices, and expectations of the office until they've settled in and "learned the ropes." We may walk into a party alone, quickly scan the room, and suddenly feel bodily disoriented by the sweep of unfamiliar faces.

Despite the differences in how this experience may manifest, this felt loss of at-home-ness is a phenomenological indication that one is no longer finding one's way. If I suddenly realise that I don't know anyone at the party, I may feel my social possibilities abruptly dissolve and be unsure what to do next. Indeed, these experiences may be uncomfortable. But feeling disoriented on the first day of work or when walking into a party full of strangers is a privileged form of disorientation that can be overcome with relative ease (e.g., spending a few days settling into the office; having a stranger come over and introduce you to other partygoers). This is because these arrangements are, for the most part, organised to generate atmospheres of inclusion. It may take some time for certain bodies to sort out how best to fit into them. But these arrangements are nevertheless designed to support and enable this process.

In other contexts, however, the discomfort of bodily disorientations can be much more intense and have significant practical and political consequences. Critical phenomenologists are helpful for understanding how so. 
Critical phenomenologists incorporate insights from feminist theorists, critical race theorists, queer theorists, decolonial and indigenous scholars, and others to highlight the ethical and political significance of traditional phenomenological debates (Salamon 2018; Weiss, Salamon, and Murphy 2019). Some critical phenomenologists have explicitly drawn our attention to powerful connections between bodily discomfort, disorientation, and the politics of space - that is, the profound, and potentially devastating, consequences of ensuring that certain kinds of bodies (e.g., non-white bodies, queer bodies) are not allowed to comfortably find their way into and through certain kinds of arrangements (e.g., Ahmed 2006, 2007; Fanon 1986; Yancy 2016). This is because certain arrangements are configured to deliberately generate what we might refer to as atmospheres of exclusion. Atmospheres of exclusion constrain certain kinds of bodies, hinder their agency and emotions, and in so doing disturb them at a pre-reflective level.

\section{Non-white bodies and atmospheres of exclusion ${ }^{4}$}

Sara Ahmed has developed a rich analysis of the environmental manipulations and bodily dynamics that generate what I'm calling "atmosphere of exclusion." She develops her analysis by drawing our attention to the constitutive relation between body and space. As she repeatedly emphasises, the character of our pre-reflective bodily experience is bound up with space-and more precisely, with specific features of the affective arrangements we inhabit. By "pre-reflective," phenomenologists like Ahmed refer to the fundamental ways we experience our body and its capacities for movement, expression, and action (i.e., our felt sense of agency) (Colombetti 2014). Our body is implicitly present as we perceive and act on the world; it shapes what we experience and how we experience it without our explicit attention from one moment to the next. Ahmed tells us that "the body is habitual insofar as it 'trails behind' in the performing of action, insofar as it does not pose 'a problem' or an obstacle to the action, or is not 'stressed' by 'what' the action encounters ... the habitual body does not get in the way of an action: it is behind the action" (Ahmed 2007, 156). Accordingly, how we feel at home in the world rests on the character of how our bodily experience anchors us in space, including the affective arrangements we inhabit. Ahmed's special contribution is to draw attention to how spaces and arrangements deprive us of at-home-ness by placing us in a state of disorientation.

Atmospheres of exclusion generate experiences of disorientation. They hinder certain bodies from finding their way. Ahmed observes that "[f]or bodies that are not extended by the skin of the social, bodily movement is not so easy" (Ahmed 2007, 161). In support of this claim, she develops a phenomenology of "being stopped," as she puts it. Black activism, Ahmed notes, highlights the many ways that policing involves a "differential economy of stopping." Some bodies - mainly non-white bodies - are stopped by 
the police more than others: e.g., being pulled over while driving, or harassed while trying to enter their own home. But being stopped often occurs in other (i.e., non-policing) contexts, too, such as when non-white bodies are bombarded with racist images or memes in online spaces, followed by suspicious neighbours in gated communities, or passed over for a job despite having equivalent (or better) qualifications than white candidates.

A key insight here is that this stopping doesn't just place practical constraints on stopped bodies by depriving them of access to certain things and spaces (although it does). It also has significant phenomenological consequences: it induces a perpetual bodily disorientation, a disturbance of that stopped body at a pre-reflective level. This is because the persistent threat of being stopped isn't an abstract or ephemeral thing. It is materially encoded within different affective arrangements designed specifically to unsettle and disorient certain bodies. A stark example is the proliferation of "Whites Only" and "Colored" signs once found above drinking fountains, waiting rooms, toilets, restaurants, and swimming pools across the American landscape well into the 20 th century. The prevalence of these signs not only signalled that non-white bodies were not allowed to access the practical resources they offered. They also indicated a lack of social possibilities. Non-white bodies were deliberately deprived of possibilities to connect and share, that is, to feel as though they were participatory members of a common history and community. ${ }^{5}$

Of course, there are many more contemporary examples. Some are obvious, such as the 2020 killing of George Floyd, an unarmed African American man killed by the police after allegedly passing a counterfeit bill in a Minneapolis grocery store. Floyd's death under the knee of a police officer inaugurated protests throughout the US and beyond, calling for a change to institutions, practices, and arrangements that systematically devalue and target non-white bodies. However, sometimes this stopping is more subtle; it occurs within arrangements that are supposed to be welcoming and inclusive. These cases reinforce the idea that affective arrangements are porous and nested. Atmospheres of exclusion can spring up within contexts that, on the surface, appear to actively cultivate atmospheres of inclusion.

Ahmed gives us an example. She talks about the experience of walking into a room and experiencing it as a malleable affective container (Ahmed 2014, 224). A non-white body can enter into a room full of academic feminists, for instance, and experience a global change in the affective tonality of the room. Even in an academic space one might think would be particularly open and inviting, a non-white body can still have the experience of being stopped. Ahmed quotes bell hooks' description of this experience: "A group of white feminist activists who do not know one another may be present at a meeting to discuss feminist theory. They may feel bonded on the basis of shared womanhood, but the atmosphere will noticeably change when a woman of color enters the room. The white women will become tense, no longer relaxed, no longer celebratory" (quoted in Ahmed 2014, 224). 
In this case, the overt reaction of the other bodies (i.e., becoming suddenly tense, less celebratory) makes it clear that the non-white body will not be able to seamlessly fit into the contours of this arrangement. Moreover, part of the bodily disorientation non-white bodies feel is not simply due to the feeling that their presence puts other bodies on edge, that is, that they are somehow affectively out-of-sync with these other bodies and not fully at home. It also arises from the recognition that they are the ones who must now work to make others comfortable with their arrival. As Ahmed puts it, "[t]hose who do not sink into spaces, whose bodies are registered as not fitting, often have to work to make others comfortable. Much of what I have earlier called 'diversity work' is thus emotional work" (24). This emotional work extracts a bodily toll. ${ }^{6}$

As these examples indicate, moving through atmospheres of exclusion-pervaded by the persistent threat of being stopped-leaves traces on stopped bodies (Ahmed 2007, 158). These traces are present not only when stopped bodies inhabit acutely threatening spaces, such as being pulled over by the police. It endures when they move on to other spaces, too. As Fanon observes, this is because stopped bodies are perpetually "surrounded by an atmosphere of certain uncertainty" (Fanon 1986, 83). Can I use this toilet? Why did that police car slow down as it drove by? Why did those white feminist scholars stiffen up when I entered the room? Why are the diners at the next table staring at me? Why is this security guard following me as I shop? For both Fanon and Ahmed, no space is entirely free from the threat of being stopped. As a result, "[t]hose who get stopped are moved in a different way" as they find their way through the world (Ahmed 2006, 162). They are disoriented at a pre-reflective bodily level, insofar as they are never allowed to fully extend and take shape within everyday arrangements white bodies take for granted.

Ahmed says that her Muslim name similarly disrupts her bodily experience. It slows her down as she finds her way through the world. This is because her body is continually marked as "could be Muslim," which is, in turn, immediately translated into "could be terrorist." She is, thus, haunted by an atmosphere of exclusion that follows her wherever she goes-simply because she has the "wrong" kind of name. This experience has bodily consequences: "[h]aving been singled out in the line, at the borders, we become defensive; we assume a defensive posture, as we 'wait' for the line of racism, to take our rights of passage away" (163). Ahmed's non-white body is brought into line with other non-white bodies also marked with "terrorist" names. In being singled out and made to wait, government authorities make clear that to be a non-white body in the west "is to be not extended by the spaces you inhabit" (163). Rather, it is to be made to feel continually out-ofsync with-disoriented by and within - those spaces and the atmosphere of "certain uncertainty," the atmospheres of exclusion that pervades them.

Ahmed's analysis is useful for many reasons. Among other things, it provides us with a rich phenomenological account of how certain bodies 
are made to feel perpetually disoriented by the structure and character of different affective arrangements they inhabit in everyday life. She draws particular attention to the way that affective arrangements, and the atmospheres of exclusion they generate, have political consequences. Equipped with this critical phenomenological framework, we can now turn to a consideration of disorientation and atmospheres of exclusion in autism.

\section{Autistic bodies and atmospheres of exclusion}

How does the previous analysis relate to autism? In short, autistic bodies are often stopped bodies. They are not allowed to fully extend into and take shape within the spaces they inhabit-affective arrangements organised primarily around the form of neurotypical bodies. This experience of not fitting in, of being hindered from finding their way, can lead autistic persons to experience a kind of pre-reflective bodily disorientation within these arrangements which, in turn, informs and intensifies some of their social difficulties. This claim has significance for understanding the nature of some social difficulties in autism as well as potential intervention strategies. These cases are also helpful for taxonomic reasons. They provide an example of arrangements that can generate atmospheres of exclusion, but which may do so (unlike some of Ahmed's examples) in ways that are unintended by those responsible for them. ${ }^{7}$

First, some brief background. Autistic people often struggle to communicate with others, become attuned to their emotions and intentions, and flexibly adapt to changing social environments. The still-dominant way of thinking about these social difficulties is the neuro-cognitive perspective (Chapman 2019, 422). According to this perspective, autistic differences can be explained by neurocognitive differences found in all autistic individuals. These differences rest on a diminished capacity for mentalising, or cognising the existence of other minds, when compared to neurotypicals (Baron-Cohen 1995). This mentalising deficit causes difficulties interpreting and predicting others' behaviour, and smoothly integrating with the shared practices that make up everyday life.

Recently, challenges to this neuro-cognitive perspective have surfaced from a number of fronts. They argue for a more holistic and multidimensional approach. Despite their other differences, these challenges collectively argue that adopting a neurocognitive perspective overlooks key embodied, interactive, relational, and developmental processes that are partly constitutive of autistic styles of thinking, expressing, and sharing emotions and experiences (Bizzari 2018; De Jaegher 2013; Krueger and Maiese 2018; Roberts, Krueger, and Glackin 2019; Schilbach 2016). Looking at experiences of disorientation and being stopped in autism can help make the importance of some of these processes clearer, as well as what role these relational factors play in shaping some social difficulties. 


\section{Joel Krueger}

There is now growing sensitivity to how autistic persons use their bodies to move through the world, express emotions, and respond to the people, things, and spaces around them (Doan and Fenton 2013). Instead of focusing exclusively on cognitive traits, they refocus on distinctive ways autistic persons pre-reflectively experience and live through their bodies as they use their bodily agency to organise sensory information and negotiate shared spaces (Boldsen 2018, Donnellan, Hill, and Leary 2012). Neuro-cognitive perspectives say little about bodily experience in ASD. But understanding the role of the body is crucial for understanding how autistic people find their way through everyday arrangements.

From a neurotypical perspective, ASD styles of embodiment can seem unusual or strange. The timing and flow of their movements may seem somehow off or contextually inappropriate. People with ASD may have an unusual gait or posture. And they sometimes have movements, tics, and habits (e.g., rocking, hand-flapping, spinning, exaggerated gestures, etc.) that neurotypicals find strange. They may also repeatedly shrug, squint, pout or rock back and forth; repeatedly touch a particular object; turn away when someone tries to engage with them; maintain an unusual or inert posture; appear "stuck" in indecisive movements for an uncomfortably long period of time; have trouble imitating actions; or require explicit prompts to perform an action.

These distinct styles of embodiment aren't simply apparent from a third-person vantage point, however. First-person reports suggest that people with autism pre-reflectively experience their body from the inside in ways that are different from neurotypical experience. The character of these anomalous bodily experiences shapes their distinctive behaviour which can, in turn, lead to difficulties fitting into neurotypical arrangements.

For example, reports indicate that people with autism often experience difficulties with movements. This includes controlling, executing, and combining movements-from fine motor control, grip planning, and anticipatory movements, to more complex actions like gesturing, reaching for a book, dancing, or negotiating a crowded hallway (Eigsti 2013). Sometimes this feeling results not just from measurable coordination difficulties but also from a felt sense of diminished agency and bodily control-including a sense that one's body has a mind of its own, particularly when stressed or overstimulated: "I had an automatic urge to touch my body-rub my thighs or my stomach and chest" (Robledo, Donnellan, and Strandt-Conroy 2012,6). At other times, individuals with ASD report difficulty feeling their limbs in relation to one another and space (Blanche et al. 2012). This spatial difficulty can make it difficult to smoothly interact with the environment. To cope, some individuals seek sustained deep pressure or joint compression to regain a felt sense of bodily integrity (Leary and Donnellan 2012, 60). Strategies include lying on the floor under a mattress or sofa cushions, jumping on the floor or bed, wearing multiple layers of clothing, banging fists on hard surfaces, or sitting in a plush 
recliner, bathtub, or swimming pool in order to have the experience of being touched over their entire body.

So, how does all this relate to atmospheres of exclusion? The key point is this: these anomalous bodily experiences can lead people with ASD to feel as though their unique styles of embodiment do not smoothly integrate with neurotypical arrangements, including patterns of interaction and normative expectations comprising these arrangements. Some of the causal factors responsible for these anomalous bodily experiences likely reside within the neurophysiology of the individual. However, some of these factors also appear to be social: individuals have the experience of being "stopped" by structures and norm-governed character of neurotypical arrangements. Accordingly, this sense of being stopped feeds into and intensifies aspects of their pre-reflective bodily disorientation when they inhabit and try to negotiate these spaces.

We can let people with ASD describe their own experiences of being stopped, as well as the feeling of bodily disorientation that ensues. ${ }^{8}$ One individual says that, "I was sitting on the floor and when I got up after looking at a couple of books, my friend said I got up like an animal does"-and further, that although she is aware that her bodily style differs from those of neurotypicals, she remains unsure of how it differs, exactly (Robledo, Donnellan, and Strandt-Conroy 2012, 6). Another says that she will often "lose the rhythm" required to perform actions involving two or more movements, and that "[e]verything has to be thought out" in advance (6), which she is aware gives her movements an excessively stiff and unnatural quality. This felt disconnection both from her own body, along with a sense that she is rhythmically out-of-sync with the neurotypical people and arrangements she inhabits - and judged negatively because of this - cause frustration. It also deepens her sense of bodily disorientation: "I have been endlessly criticized about how different I looked, criticized about all kinds of tiny differences in my behavior ... No one ever tried to really understand what it was like to be me ..." (6). For many people with ASD, negotiating neurotypical arrangements involves negotiating an "atmosphere of certain uncertainty," as Fanon puts it. These arrangements are not set up to accommodate or be responsive to non-neurotypical styles of embodiment and expression. This can lead to the feeling that one is always about to be negatively impacted or judged for not settling into the bodily dynamics of these spaces in a comfortably familiar (i.e., neurotypical) way.

There are many more reports like these (see Leary and Donnellan 2012). They suggest that autistic bodies struggle to extend themselves into arrangements organised around the form, and norms, of neurotypicals people and practices. Forms of engagement, expression, and sharing acceptable within ASD forms of life are often actively discouraged and negatively evaluated within neurotypical arrangements. This pervasive resistance gives rise to experiences of atmospheres of exclusion. These atmospheres limit bodily possibilities for people with ASD. Additionally, they shape their feeling of 


\section{Joel Krueger}

being bodily stopped. This resistance might be acutely felt when negotiating the material structure of different neurotypical arrangements such as a noisy, brightly lit lecture hall, restaurant, or retail space that negatively impacts an individual's auditory and visual hypersensitivity. But it can also be felt in different ways within interpersonal contexts, too.

Consider delayed responses in conversation. Autistic people are often thought to struggle with the back-and-forth flow of conversations. Yet, Donnellan and colleagues found that twelve young adolescents with minimal verbal skills, all of whom were labelled developmentally disabled or autistic, could offer competent conversational responses-but only, on average, after 14 seconds of silence (Leary and Donnellan 2012, 57). Most neurotypicals would find this slower-paced rhythm awkward. It would alter the character of that interaction in an unfamiliar way (i.e., for neurotypicals), and they would probably change the subject or leave the conversation altogether.

Consider another conversational example: when someone is asked a question like "Do I look good in this shirt?" An autistic person might see this question as fact-seeking and give an honest and direct answer ("No, you do not"). However, sensitive attunement to the broader context in which it is asked might show that the asker is actually seeking not information but affirmation ("Sure, you look great!"), or at least honest but gentle critical feedback ("Hmm, not bad, but perhaps we can find a more flattering color"). So, a direct and honest answer from an autistic person might be met with confusion, a hurt reaction, and lead to conflict - all of which they may find puzzling and disorienting. Repeated experiences of this sort may discourage them from future engagements. They further intensify the sense that neurotypical arrangements create atmospheres that perpetually exclude them.

Note, however, that this lack of social sensitivity and feeling of fitting in cuts both ways. As McGeer notes, people with ASD may be "blind to our minds, but so too are we blind to theirs" (McGeer 2009, 524). Seeing how so helps to further highlight the spatial origin of some social impairments in ASD. For example, within autistic spaces, it is normal and acceptable for autistics to avoid eye contact when speaking to someone. Within neurotypical spaces, however, people who do this are often seen as deceptive or dishonest. Similarly, neurotypicals may find rhythmic patterns of "selfstimulation" (or "self-stims")-hand-flapping, finger-snapping, tapping objects, repetitive vocalisations, or rocking back and forth, etc.-socially off-putting, and view them as meaningless behaviour. Indeed, treatment programs (often developed with little input from autistic people) have traditionally tried to suppress or eliminate them (Azrin, Kaplan, and Foxx 1973). Yet, for many autistic people, self-stims are embodied strategies for managing sensory information and finding their way. They may use them to refocus and self-regulate when information threatens to be overwhelming (hypersensitivity), or when they require heightened arousal in order to access further 
information (hyposensitivity). While people with ASD may be actively discouraged from bodily extending themselves via these strategies within neurotypical spaces, they nevertheless have the freedom to do so within autistic arrangements where their meaning and salience is recognised. ${ }^{10}$

The takeaway lesson is that many of the social difficulties autistic people exhibit are context sensitive. They are the result of atmospheres of exclusion arising from neurotypical arrangements not adequately configured to accommodate diverse styles of bodily being-in-the-world. These atmospheres are the source of much of the bodily disorientation people with ASD feel in their everyday life. Tellingly, these same social difficulties do not arise when people with ASD inhabit autistic arrangements-atmospheres of inclusion-where these bodily practices are viewed as acceptable strategies for finding one's way. As one autistic person tells us: "If I socialize with other Aspergians of pretty much my own functionality, then all of the so-called social impairments simply don't exist ... we share the same operating systems, so there are no impairments" (Cornish 2008, 158). Reports like these are supported by studies indicating that while high-functioning autistic people may feel anxiety and encounter difficulties interacting with non-autistic people, they nevertheless find their interactions with other autistic persons efficient and pleasurable (Schilbach 2016; see also Komeda et al. 2015). Again, the latter are governed by ASD-friendly norms, expectations, and social possibilities that allow them to bodily extend into those arrangements in ways they cannot when they inhabit many neurotypical spaces.

\section{Conclusion}

I've argued that atmospheres do things. They have a profound regulative power to actively shape experience, behaviour, and forms of social connection. This regulative power, I've argued further, comes from the fact that atmospheres do more than just provide affective colour or texture to the world. They also furnish possibilities: ways to act on the world, ways to fit into the spaces and arrangements we negotiate, alone and with others, throughout everyday life. What I've termed "atmospheres of inclusion" and "atmospheres of exclusion," applied to Sara Ahmed's critical phenomenology of stopped bodies and social difficulties in autism, can show how atmospheres both help and hinder as we find our way.

To be clear, none of the above should be read as suggesting that the ontological focus characterising many ongoing philosophical discussions of atmospheres is a waste of time. It's not. For, despite their ubiquity in everyday life, atmospheres remain an elusive phenomenon. Clarifying their nature, therefore, remains a philosophically useful project. Instead, this analysis should be read as a reminder that atmospheres make a concrete difference in our lives. This is true not just in terms of enhancing our aesthetic and emotional experience. They also allow us to fit into our world, to feel at 
home in it (or, as we've seen, become disoriented). In other words, they have a profound political and ethical significance worthy of ongoing philosophical attention. Resources from critical phenomenology can help us find our way through some of these issues.

\section{Notes}

1 Slaby and colleagues are hesitant to use the term "atmosphere" for some of the reasons I describe above. Moreover, they say that on some, but not all occasions, the overall affective dynamics that make up affective arrangements can be aptly described as affective atmospheres (ibid., footnote 24). However, it's not clear to me that an affective arrangement, under their characterisation, can fail to generate some sort of atmospheric properties. Even an affective arrangement that, for whatever reason, fits together in a discordant or incongruous way will nevertheless still have an overall unifying feel or affective tonality - an atmosphere. So, I will use "affective arrangements" and "atmospheres" in roughly the same way, even if that departs from Slaby et al.'s precise usage.

2 Michelle Maiese (2018) has recently explored similar themes with her rich analysis of the interrelation between social institutions and embodied "habits of mind."

3 Although I don't discuss the Internet here, online spaces can function as affective arrangements. See, e.g., Osler (2020), Krueger and Osler (2019), and Osler and Krueger (forthcoming) for more discussion, including a discussion of why the "online/offline" distinction is increasingly less tenable.

4 The discussion in this section and the next has been adapted and expanded from analysis in Krueger (forthcoming).

5 It is often assumed that these signs were confined to the South. But this is not the case - and some could still be found throughout various parts of the US into the 1970s (Abel 2010).

6 As we'll see, people with autism sometimes describe a similar experience.

7 I here follow the terminological preferences of neurodiversity proponents who, by endorsing identity-first language ("autistic persons") instead of person-first language ("individuals with autism"), deliberately stress the connection between cognitive styles and selfhood (Pellicano and Stears 2011).

8 Chapman (2019) observes that first-person reports of autistic people are often left out of philosophical and psychological discussions of autism (p. 426).

9 This example is taken from Chapman (2019, p. 430).

10 Observations such as these helps explain why the Internet is so important for providing spaces for autistic people to develop online arrangements governed by autistic norms, vocabularies, and styles of expression (Hacking 2009). See Osler (forthcoming) for a phenomenological discussion of how the lived body can enter online spaces and be empathically available to others within those spaces.

\section{References}

Abel, Elizabeth. 2010. Signs of the Times: The Visual Politics of Jim Crow. Berkeley: University of California Press.

Ahmed, Sara. 2006. Queer Phenomenology: Orientations, Objects, Others. Durham: Duke University Press. 
2007. "A Phenomenology of Whiteness." Feminist Theory 8 (2): 149-168.

Press.

Anderson, Ben. 2009. "Affective Atmospheres." Emotion, Space and Society 2 (2): 77-81.

Azrin, N. H., S. J. Kaplan, and R. M. Foxx. 1973. "Autism Reversal: Eliminating Stereotyped Self-Stimulation of Retarded Individuals." American Journal of Mental Deficiency 78 (3): 241-248.

Baron-Cohen, Simon. 1995. Mindblindness: An Essay on Autism and Theory of Mind. Cambridge: MIT Press.

Bizzari, Valeria. 2018. "Like in a Shell: Interaffectivity and Social Cognition in Asperger's Syndrome." Thaumàzein 6: 158-179.

Blanche, Erna Imperatore, Gustavo Reinoso, Megan C. Chang, and Stefanie Bodison. 2012. "Proprioceptive Processing Difficulties among Children with Autism Spectrum Disorders and Developmental Disabilities." The American Journal of Occupational Therapy: Official Publication of the American Occupational Therapy Association 66 (5): 621-624.

Böhme, Gernot. 1993. "Atmosphere as the Fundamental Concept of a New Aesthetics." Thesis Eleven 36 (1): 113-126.

- 2006. "Atmosphere as the Subject Matter of Architecture." In Herzog and Meuron: Natural History, edited by P. Ursprung, 398-407. London: Lars Muller Publishers.

Boldsen, Sofie. 2018. "Toward a Phenomenological Account of Embodied Subjectivity in Autism." Culture, Medicine and Psychiatry 42(4): 893-913.

Carel, Havi. 2016. Phenomenology of Illness. Oxford: Oxford University Press.

Chapman, Robert. 2019. "Autism as a Form of Life: Wittgenstein and the Psychological Coherence of Autism." Metaphilosophy 50 (4): 421-440.

Colombetti, Giovanna. 2014. The Feeling Body: Affective Science Meets the Enactive Mind. Cambridge, MA: MIT Press.

. 2016. "Affective Incorporation." In Phenomenology for the Twenty-First Century, edited by J. Aaron Simmons and J. Edward Hackett, 231-248. London: Palgrave Macmillan UK.

Colombetti, Giovanna, and Joel Krueger. 2015. "Scaffoldings of the Affective Mind." Philosophical Psychology 28 (8): 1157-1576.

Colombetti, Giovanna, and Tom Roberts. 2015. "Extending the Extended Mind: The Case for Extended Affectivity." Philosophical Studies 172 (5): 1243-1263.

Cornish. 2008. "A Stranger in a Strange Land: A Journey Through the Social Weirdness of the Neurotypical." In Asperger's Syndrome and Social Relationships, edited by Genevieve Edmonds and Luke Beardon, London: Jessica Kingsley Publishers, 151-160.

De Jaegher, Hanne. 2013. "Embodiment and Sense-Making in Autism.” Frontiers in Integrative Neuroscience 7 (15): 1-19.

Doan, Michael, and Andrew Fenton. 2013. "Embodying Autistic Cognition: Towards Reconceiving Certain 'Autism-Related' Behavioural Atypicalities as Functional.” In The Philosophy of Autism, edited by Jamie L. Anderson and Simon Cushing, 47-71. New York: Rowman and Littlefield Publishers Inc.

Donnellan, Anne M., David A. Hill, and Martha R. Leary. 2012. "Rethinking Autism: Implications of Sensory and Movement Differences for Understanding and Support." Frontiers in Integrative Neuroscience 6 (124): 1-11. 
Eigsti, Inge-Marie. 2013. "A Review of Embodiment in Autism Spectrum Disorders." Frontiers in Psychology 4 (224): 1-10.

Fanon, Frantz. 1986. Black Skin, White Masks. Translated by Charles Lam Markmann. London: Pluto Press.

Gregg, Melissa. 2011. Work's Intimacy. Cambridge: Polity.

Griffero, Tonino. 2014. Atmospheres: Aesthetics of Emotional Spaces. Burlington, VT: Ashgate Publishing, Ltd.

Griffiths, Paul, and Andrea Scarantino. 2009. "Emotions in the Wild: The Situated Perspective on Emotion." In The Cambridge Handbook of Situated Cognition, edited by M. Aydede and P. Robbins, 437-53. Cambridge: Cambridge University Press.

Hacking, Ian. 2009. "Autistic Autobiography." Philosophical Transactions of the Royal Society of London. Series B, Biological Sciences 364 (1522): 1467-1473.

Komeda, Hidetsugu, Hirotaka Kosaka, Daisuke N. Saito, Yoko Mano, Minyoung Jung, Takeshi Fujii, Hisakazu T. Yanaka, et al. 2015. "Autistic Empathy toward Autistic Others." Social Cognitive and Affective Neuroscience 10 (2): 145-152.

Krueger, Joel, and M. Maiese. 2018. "Mental Institutions, Habits of Mind, and an Extended Approach to Autism." Thaumàzein 6: 10-41.

Krueger, Joel. 2014a. "Affordances and the Musically Extended Mind." Frontiers in Psychology 4 (1003): 1-13.

. 2014b. "Varieties of Extended Emotions." Phenomenology and the Cognitive Sciences 13 (4): 533-555.

Krueger, Joel, and Lucy Osler. 2019. "Engineering Affect: Emotion Regulation, the Internet, and the Techno-Social Niche." Philosophical Topics 47 (2): 205-231.

Leary, Martha R., and Anne M. Donnellan. 2012. Autism: Sensory-Movement Differences and Diversity. Cambridge: Cambridge Book Review Press.

Maiese, Michele. 2018. "Life Shaping, Habits of Mind, and Social Institutions." Natureza Humana - Revista Internacional de Filosofia E Psicanálise 20 (1): 4-28.

Maiese, Michelle, and Robert Hanna. 2019. The Mind-Body Politic. London: Palgrave Macmillan.

Mcgeer, Victoria. 2009. "The Thought and Talk of Individuals with Autism: Reflections on Ian Hacking." Metaphilosophy 40 (3-4): 517-530.

Osler, Lucy. 2020. "Feeling Togetherness Online: A Phenomenological Sketch of Online Communal Experiences." Phenomenology and the Cognitive Sciences 19 (3): $569-588$.

- 2021. "Interpersonal Atmospheres: An Empathetic Account." University of Exeter. https://ore.exeter.ac.uk/repository/handle/10871/124306.

—. 2021. "Taking empathy online," Inquiry, doi:10.1080/0020174X.2021.1899045

Osler, Lucy, and Joel Krueger. Forthcoming. "Taking Watsuji Online: Betweenness and Expression in Online Spaces." Continental Philosophy Review

Pellicano, Elizabeth, and Marc Stears. 2011. "Bridging Autism, Science and Society: Moving toward an Ethically Informed Approach to Autism Research." Autism Research: Official Journal of the International Society for Autism Research 4 (4): 271-282.

Roberts, Tom, Joel Krueger, and Shane Glackin. 2019. "Psychiatry Beyond the Brain: Externalism, Mental Health, and Autistic Spectrum Disorder.” Philosophy, Psychiatry, \& Psychology: PPP 26 (3): E - 51-E - 68.

Robledo, Jodi, Anne M. Donnellan, and Karen Strandt-Conroy. 2012. "An Exploration of Sensory and Movement Differences from the Perspective of Individuals with Autism." Frontiers in Integrative Neuroscience 6 (107): 1-13. 
Saarinen, Jussi A. 2020. "What Can the Concept of Affective Scaffolding Do for Us?" Philosophical Psychology 33 (6): 820-839.

Salamon, Gayle. 2018. "What's Critical about Critical Phenomenology?" Journal of Critical Phenomenology 1 (1): 8-17.

Schilbach, Leonhard. 2016. "Towards a Second-Person Neuropsychiatry." Philosophical Transactions of the Royal Society of London. Series B, Biological Sciences 371 (1686): 20150081.

Schmitz, Hermann. 2019. New Phenomenology: A Brief Introduction. Mimesis.

Slaby, Jan. 2014. "Emotions and the Extended Mind." In Collective Emotions, edited by Mikko Salmela and Christian Von Scheve, 32-46. Oxford: Oxford University Press.

- 2016. "Mind Invasion: Situated Affectivity and the Corporate Life Hack." Frontiers in Psychology 7 (266): 1-13.

. 2019. "Atmospheres-Schmitz, Massumi and beyond." Music as Atmosphere: Collective Feelings and Affective Sounds, edited by Friedlind Riedel and Juha Torvinen. London: Routledge.

Slaby, Jan, Rainer Mühlhoff, and Philipp Wüschner. 2017. "Affective Arrangements." Emotion Review: Journal of the International Society for Research on Emotion 11 (1):3-12. doi:10.1177/1754073917722214

Stephan, Achim, Sven Walter, and Wendy Wilutzky. 2014. "Emotions beyond Brain and Body." Philosophical Psychology 27 (1): 65-81.

Svenaeus, Fredrik. 2019. "A Defense of the Phenomenological Account of Health and Illness." The Journal of Medicine and Philosophy 44 (4): 459-478.

Tschaepe, Mark. 2021. "Somaesthetics of Discomfort: Enhancing Awareness and Inquiry." European Journal of Pragmatism and American Philosophy XIII (1): 1-10.

Von Maur, Imke. 2021. "Taking Situatedness Seriously. Embedding Affective Intentionality in Forms of Living." Frontiers in Psychology 12 (5999939): 1-14.

Weiss, Gail, Gayle Salamon, and Ann V. Murphy. 2019. 50 Concepts for a Critical Phenomenology. Evanston: Northwestern University Press.

Yancy, George. 2016. Black Bodies, White Gazes: The Continuing Significance of Race in America. Lanham, MD: Rowman \& Littlefield. 